\title{
Marchiafava-Bignami's Disease, as Etiologic Diagnosis of Athetosis
}

\author{
Alberto Vargas Canas ${ }^{\mathrm{a}, \mathrm{c}}$ Mario Rivas ${ }^{\mathrm{a}}$ Rodrigo Guerrero Torrealba ${ }^{\mathrm{a}}$ \\ María Francisca Fajre Caamano ${ }^{b}$ \\ a Unidad de Neurología Hospital Santiago Oriente "Dr. Luis Tisné", b Interna de Medicina, Universidad de los Andes \\ de Chile, and 'Investigador Internacional Universidad Autónoma del Caribe, Santiago, Chile
}

\section{Keywords}

Marchiafava-Bignami disease $\cdot$ Athetosis $\cdot$ Corpus callosum

\begin{abstract}
The Marchiafava-Bignami disease, characterized by demyelination and necrosis of the corpus callosum, has typically been associated with chronic alcohol intake, and clinically has various symptoms and signs. However, several cases have been reported without alcohol association, and these - according to several publications - have some common points, such as preference for female, related to malnutrition, and radiological involvement of the splenium of the corpus callosum. We report a case of a patient with the characteristics described above and whose clinical manifestation was Athetosis. The authors associate this manifestation with the somatotopic distribution of the corpus callosum, and contribute to the etiologic diagnosis of Athetosis as a manifestation of the Marchiafava-Bignami disease, which has not been reported in the medical literature according to our review of the database.

(C) 2017 S. Karger AG, Basel
\end{abstract}

\section{Introduction}

Marchiafava-Bignami's disease, abbreviated as MBD, is a clinical entity typically associated with chronic intake of alcohol. MBD was initially described in 1903 by the
Italian pathologists Marchiafava and Bignami, and is characterized by demyelination and necrosis of the corpus callosum [1]. The clinical presentation is conspicuous; however, it is most often manifested with neuropsychiatric symptoms, dysarthria, ataxia-abasia, and interhemispheric disconnection syndrome [2]. In addition to the association with alcohol intake, it has also been strongly associated with malnutrition, with a tendency toward remission when nutrition is restored. There are also reports of improvement after the administration of thiamine [3]. Cases of non-alcoholic origin are rare even in the low frequency of MBD, so it is important for the medical community to include them.

In this study, we report the case of a patient who presented with athetosis and whose complementary studies showed radiological findings of MBD. Also a review of the literature was done with the aim of defining the imaging features clearly and supporting in the explanation of athetosis as a clinical manifestation of MBD.

\section{Case Report}

A 34-year-old woman, with no previous morbid history, presented last year with a quick 1 week installation of restlessness followed by involuntary movements of hands and legs, predominantly in the upper extremities, which disappeared completely during sleep. She also complained of development of gait difficulty, falls, and minimal dysarthria. The severity of symptoms was constant over time. When interrogated about the previous year, a history of weight loss of $10 \mathrm{~kg}$ and an anemic syndrome
KARGER

(c) 2017 S. Karger AG, Basel

E-Mail karger@karger.com

www.karger.com/aon
Alberto Vargas Canas, MD

Department of Neurology, Santiago Oriente Hospital

Av. Las Torres 5150, Penalolen

Santiago (Chile)

E-Mailamvc_md@yahoo.com 
that reverted with iron supplements and folic acid came to our knowledge. On physical examination, athetosis was found predominantly in the upper extremities, also hypotonia and hyperreflexia with an increase of the reflexogenic area in the 4 limbs. The complete blood count, liver biochemical profile, syphilis, $\mathrm{VIH}$ test, and serum ceruloplasmin were within normal ranges and/or negative.

The study was completed with CT (Fig. 1), which showed a hypodense region in the splenium of the corpus callosum, and nuclear MRI was compatible MBD (Fig. 2).

By ethical considerations, the patient was asked to consent to publish her clinical case in a medical journal, with affirmative answer.

\section{Analysis}

Prior to the implementation of imaging studies, the diagnosis of MBD was done based on postmortem pathological findings, because the manifestations were diverse and no clinical diagnostic criteria were defined for the disease [4]. Currently, the CT images and MRI allow "in vivo" diagnosis of this condition [5], allowing the initiation of early treatment in an attempt to achieve an improvement in the living conditions of patients.

The classic features described for imaging in MRI diagnosis of MBD are diffuse atrophy of the corpus callosum and areas of focal necrosis, which present as hypointensity on T1 and hyperintensity on T2 [6]. Most of the findings are distributed throughout the corpus callosum (splenium, body, and knee), and injuries seen in the acute phase usually persist in the chronic phase and are often described as gadolinium uptake, without the latter being an exclusive criterion [7].

Among the reported cases of non-alcoholic MBD, evaluated by MRI, none presented with gadolinium contrast enhancement. In turn, most of them showed selective compromise of the splenium of the corpus callosum [8]. So far both findings could be described as common characteristics of MRI in non-alcoholic MBD.

With the advancement of functional imaging studies, it has been shown that the corpus callosum has a topographic distribution of different functions that connect from one hemisphere to another [9]. Wahl et al. [10] showed that motor human corpus callosum fibers have a somatotopic organization, where hand motor fibers are located above the feet. Although it is an initial approximation to the study of coordination of interhemispheric movement, in this series, 2 of 12 cases presented a variety of this distribution, finding the feet fibers in front of the hands fibers. Greater accuracy of functional localization of the corpus callosum could

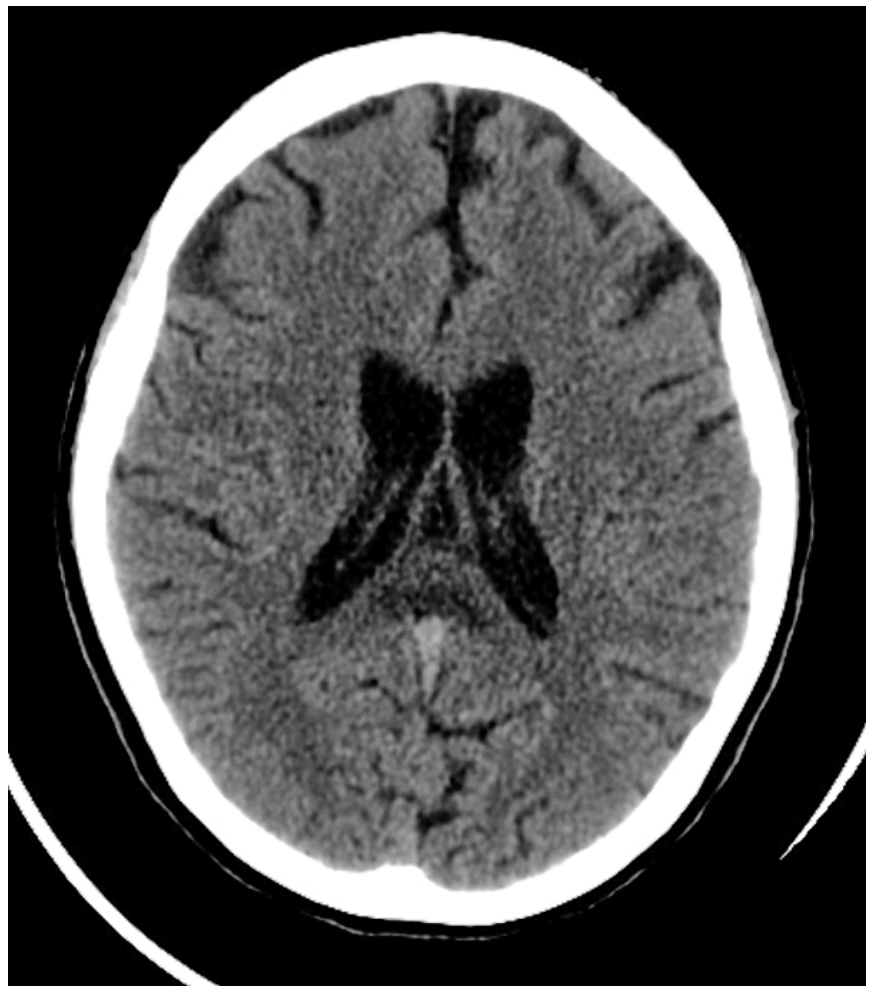

Fig. 1. TC showing hypodense corpus callosum splenium.

eventually help correlate the clinical manifestations of the MBD.

Common features of non-alcoholic MBD - according to a recent review - are female patients, young population, and those associated with malnutrition [7], all of which were present in out patients, as well as the imaging study which shows selective engagement of the splenium of corpus callosum, also described in other cases of the disease without alcohol involvement [8].

In our case report, the patient did show abnormal involuntary movements of hands and feet, consistent with athetosis. Subsequently, the CT and MR imaging findings presented MBD. So we postulate MBD as the possible etiology of acquired athetosis.

The term athetosis, comes from a Greek word meaning "without attachment" or "changing." The disease is characterized by the inability to maintain a single position in the fingers and toes, tongue or any other part of the body where no muscle group is respected and movements are slower than in chorea, and with distal predominance [11]. This seems to be related to a failure of the striatum to suppress the activity of unwanted muscle groups [3]. Among the etiologies of athetosis, are postnatal congenital hypoxia, head trauma, and perinatal ker- 

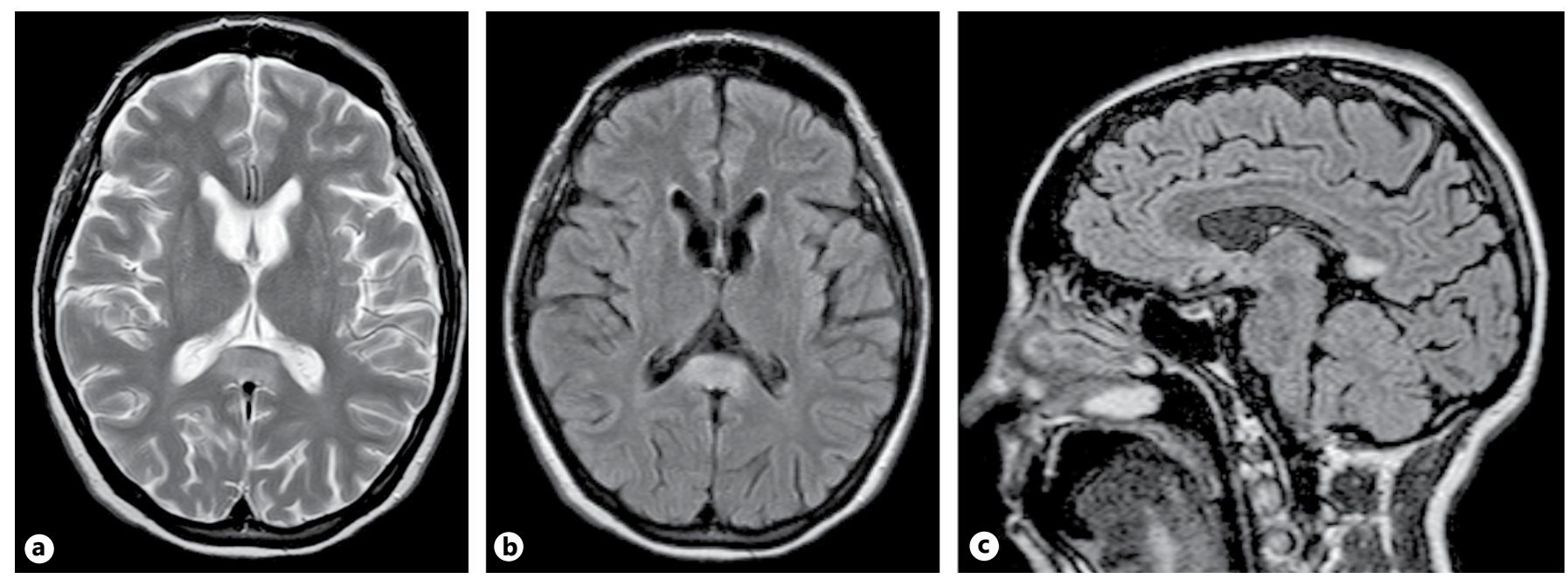

Fig. 2. RNM cerebral T2 (a), FLAIR_longTR y (b) T2WFLAIRII (c) showing hyperintensity in corpus callosum splenium.

nicterus; with neuronal loss and demyelination that affect the basal ganglia in the latter $[3,12]$. In adults, other causes of athetosis have been described, such as hepatic encephalopathy, Wilson disease, Hallervorden-Spatz Syndrome, Leigh disease, and mitochondrial disease [3]. While there is no direct evidence that MBD may be an etiological cause of athetosis, there are reports of $\mathrm{MBD}$ with impaired basal ganglia structures, athetoid cerebral palsy and multiple subcortical lesions that include the corpus callosum; this, despite not being compromised in classic description of both diseases [13, 14]. Histopathological studies of Lechevalier et al. [13] in 1977 described injuries in caudate putamen and interhemispheric disconnection in a patient with clinical MBD. Yoshida et al. [14] evaluated the anatomy of the gray and white matter in children with cerebral palsy and athetoid characteristics with MRI findings, and described a case of slight thinning of the corpus callosum. As the somatotopic distribution of motor fibers in the callosum of hands and toes are next to each other, as demonstrated in studies of functional imaging [10]; this could explain that any damage located in that area could compromise the movement of hands and feet as in athetosis.

\section{Conclusions}

From the case report and review of literature, it can be concluded that in the low frequency of non-alcoholic $\mathrm{MBD}$, this presented as common characteristics: is most common in female patients, young people, those associated with malnutrition, and the studies by MRI without

Marchiafava-Bignami's Disease, as

Etiologic Diagnosis of Athetosis gadolinium contrast enhancement show a preferential involvement of the splenium of the callosum corpus.

Our patient presented as an acquired athetosis; without other possible causes of extrapyramidal disease; with neuroimaging compatible with MBD, and after a review of the literature, with an etiological relationship to MBD which has not been previously described in literature.

An involvement of basal ganglia in MBD, and damage to the corpus callosum in athetoid cerebral palsy has been reported. Also, there is evidence of a somatotopic distribution in the corpus callosum described as an adjacent location of fibers of coordination and toes movement in the corpus callosum, which could explain that any alteration in that area could produce athetosis. Therefore, one cannot rule out the possibility that the MBD can be a cause of acquired athetosis and there is a need for more studies or other reports to assess the direct relationship between MBD and athetosis.

\section{Authorship Contribution}

A.V.C. involved in the conception, design, acquisition of data, analysis, interpretation of data, and final approval. Critically revising, analysis and final approval done by M.R.L. and R.G.T. conception, design, acquisition of data, analysis, interpretation of data done by M.F.F.C.

\section{Disclosure Statement}

The author declares no conflict of interest. This study received no funding of any form. 


\section{References}

1 Marchiafava E, Bignami A: Sopra un'alterazione del corpo calloso osservata in soggetti alcoolisti. Riv Pathol Nerv 1903;8: 544-549.

2 Murthy SB, Jawaid A, Bock JE, Qureshi SU, Schulz PE: Marchiafava-Bignami Disease (MBD) in a nonalcoholic patient: a case report. Can J Neurol Sci 2010;37:138-140.

3 Ropper AH, Brown RH: Principios de Neurología de Adams y Victor, ed 8. McGraw Hill, 2007.

4 Koeppen AH, Barron KD: Marchiafava-Bignami disease. Neurology 1978;28:290-294.

5 Heinrich A, Runge U, Khaw AV: Clinicoradiologic subtypes of Marchiafava-Bignami disease. J Neurol 2004;251:1050-1059.

6 Chang KH, Cha SH, Han MH, Park SH, Nah DL, Hong JH: Marchiafava-Bignami disease: serial changes in corpus callosum on MRI. Neuroradiology 1992;34:480-482.
7 Hillbom M, Saloheimo P, Fujioka S, Wszolek ZK, Juvela S, Leone MA: Diagnosis and management of Marchiafava-Bignami disease: a review of CT/MRI confirmed cases. J Neurol Neurosurg Psychiatry 2014;85:168173.

8 Caulo M, Briganti C, Notturno F, Committeri G, Mattei PA, Tartaro A, Gallucci M, Uncini A: Non-alcoholic partially reversible Marchiafava-Bignami disease: review and relation with reversible splenial lesions. A case report and literature review. Neuroradiol J 2009;22: 35-40.

9 Fabri M, Polonara G: Functional topography of human corpus callosum: an fMRI mapping study. Neural Plast 2013;2013:251308.

10 Wahl M, Lauterbach-Soon B, Hattingen E, Jung P, Singer O, Volz S, Klein JC, Steinmetz $\mathrm{H}$, Ziemann U: Human motor corpus callosum: topography, somatotopy, and link be- tween microstructure and function. J Neurosci 2007;27:12132-12138.

11 Vargas A, Court J: Extrapiramidal dictionary: athetosis. Rev Chil Neuro-Psiquiat 1996;34: 215-216.

12 Przekop A, Sanger TD: Birth-related syndromes of athetosis and kernicterus; in Weiner WJ, Tolosa E (eds): Hyperkinetic Movement Disorders, 2011, vol 100, pp 387-398.

13 Lechevalier B, Andersson JC, Morin P: Hemispheric disconnection syndrome with a "crossed avoiging" reaction in a case of Marchiafava-Bignami disease. J Neurol Neurosurg Psychiatry 1977;40:483-497.

14 Yoshida S, Hayakawa K, Oishi K, Mori S, Kanda T, Yamori Y, Yoshida N, Hirota H, Iwami M, Okano S, Matsushita H: Athetotic and spastic cerebral palsy: anatomic characterization based on diffusion-tensor imaging. Radiology 2011;260:511-520. 